\title{
Critical care in Malawi: The ethics of beneficence and justice
}

\author{
Lucinda Manda-Taylor ${ }^{1}$, Samson Mndolo², Tim Baker ${ }^{2,3}$ \\ 1 Centre for Bioethics in Eastern and Southern Africa (CEBESA), College of Medicine, University of Malawi, \\ Blantyre, Malawi \\ 2 Department of Anaesthesia \& Intensive Care, Queen Elizabeth Central Hospital, Blantyre, Malawi \\ 3 Global Health - Health Systems \& Policy, Department of Public Health Sciences, Karolinska Institutet, \\ Stockholm, Sweden
}

\section{Introduction}

Malawi now has its first paediatric intensive care unit (PICU). This is the first dedicated unit in the country for the care of critically ill children and children who have undergone major surgery requiring post-operative ventilation. The six-bedded ward is part of the new Paediatric Surgical Unit in Queen Elizabeth Central Hospital in Blantyre. The opening of the PICU gives us an opportunity to reflect on the great need for critical care in Malawi and the ethical challenge of caring for critically ill patients when resources are limited.

\section{The burden of critical illness}

Critical illness is any immediately life-threatening disease or injury. Critical illness is not limited by the age, gender or social status of the patient or by the medical specialty within which their condition is managed. Globally, critical illness results in several million deaths each year. ${ }^{1}$ Hospitals in high-resource settings reserve $3-5 \%$ of beds for the critically ill, and it is expected that this will increase to $20-30 \%$ as demographics change and the treatment potential of medical therapies advance. $^{2}$ While there are no data about the number of critically ill in Malawi, over $90 \%$ of deaths from acute conditions such as trauma, maternal illnesses and infections are in low and middle income countries. ${ }^{3-5}$ Using global data extrapolated from the USA, ${ }^{1}$ it can be estimated that there are between 400,000 and 500,000 cases of sepsis (one cause of critical illness) in Malawi each year. In 2012, over 18000 trauma patients were admitted to four district hospitals in rural Malawi. ${ }^{6}$ The maternal mortality ratio remains over 500 per 100000 live births, ${ }^{7}$ and one study found that $62 \%$ of maternal deaths occurred in health facilities. ${ }^{8}$ Clearly Malawi has a very large burden of critical illness.

\section{Meeting the needs of critically ill patients}

A critically ill patient requires identification and appropriate medical management. The classic "A, B, C" (airway, breathing and circulation) triad of critical illness helps to alert health care providers that the patient's life is in danger, and actions must be quick. The patient may require oxygen, intravenous fluids, antibiotics, assistance with breathing or a blood transfusion. And thereafter needs close observation, continual assessment and frequent treatment modifications. These therapies and actions, carried out by doctors, nurses and other health workers, are collectively known as "critical care".

Critical care focuses on illness severity rather than definitive diagnosis and emphasises the life-saving and supportive therapies that maintain vital organ functions. The first principles of critical care date back to Florence Nightingale in the 1850s and her reorganisation of hospital wards so that the sickest patients were closest to the nurses' stations. Reserving a section of a ward, or a particular ward, for the critically ill or "High Dependency Unit" HDU, is a common strategy throughout the world. HDUs commonly provide a higher ratio of nurses to patients, closer observation and more frequent treatment modifications, and some specialised treatments such as oxygen or suction.

Since their introduction in the 1950s Intensive Care Units (ICUs) have become commonplace in hospitals in highincome countries. ICUs provide more advanced care than HDUs, and enable such therapies as mechanical ventilation, dialysis and regulated infusions of fluids and drugs. ICUs can be resource-intensive both in terms of personnel sometimes one nurse for each patient and many members of multidisciplinary teams - and material and medical resources. The cost of ICU care in four European countries has been reported as $€ 1168$ to $€ 2025$ per patient per day. ${ }^{9}$ Although absolute numbers are lower in countries with less resources, the average cost per day of treating one patient in an ICU in a public hospital in Bombay, India was \$57 in 1999. ${ }^{10}$

\section{Critical care in Malawi}

Although the first report of an African ICU was in 1969, ${ }^{11}$ critical care remains under-developed in low resource settings. ${ }^{1,12-15}$ For example, hospitals in Africa were found to lack the necessary critical care resources to follow international sepsis guidelines. ${ }^{16,17}$ The few existing reports from ICUs in low resource settings indicate high mortality rates of $27 \%$ to $82 \%{ }^{18-23}$

In Malawi, the first ICU was established at Kamuzu Central Hospital in Lilongwe in 1990. The ICU now has a capacity of five beds. ${ }^{24}$ The Queen Elizabeth Central Hospital in Blantyre, Zomba Central Hospital in Zomba and Mzuzu Central Hospital in the northern region each have fourbedded ICUs. Mwaiwathu and Blantyre Adventist Hospitals, non-governmental hospitals in Blantyre, also have fourbedded ICUs, ${ }^{25}$ providing a national total of 25 ICU beds prior to the opening of the PICU to serve a population of 17 million. All are general ICUs providing care for all types of patients. ${ }^{25}$ HDUs can be found in some hospitals, including in several general wards in Queen Elizabeth Central Hospital.

\section{Queen Elizabeth Central Hospital}

Queen Elizabeth Central Hospital, with a bed capacity of 1200, serves a population of 5.5 million. 23,000 children are admitted annually. It can be estimated that, at any given moment in time, 30 to 50 paediatric inpatients are critically ill (personal communication Dr Q. Dube, Head of Department 
of Paediatrics). The established four-bedded ICU caters for both children and adults, admitting approximately 350 patients per year and with an ICU mortality rate of $23.6 \%{ }^{26}$

\section{Beneficence and justice}

When contemplating critical care in Malawi, the primary ethical consideration concerns the principles of beneficence and justice. Beneficence is "a positive requirement to do good to others". ${ }^{27}$ The principle of beneficence is closely related to non-maleficence, that stipulates the obligation, Primum non nocere ("first of all, do no harm"). ${ }^{27}$ Combined, these two principles assert that each action must produce more good than harm to the individual patient. Justice relates to "fairness", and implies that everyone should be treated equally, fairly and impartially. ${ }^{27}$ The principle of justice requires that we take the perspective of the whole population and balance competing values and interests while at the same time recognizing that decisions that provide benefit to one group of patients may result in harm to another. ${ }^{28}$

In the context of providing care for critically ill patients, we need to employ moral reasoning involving the potential benefits and harms to individuals and the justice effects on the population. As described above, there is a great need in Malawi for critical care services, but an inadequate supply of ICU beds. This results in hard ethical decisions about which critically ill patient should be given ICU care. This "rationing" involves the requirement to deny potentially beneficial treatment to a patient on the grounds of scarcity. ${ }^{29}$ Rationing implies that, because of cost constraints, not everyone will get every service they need; want or even deserve. ${ }^{30}$ When demand outstrips supply, health care providers deal with making allocation decisions based on perceived prioritization. ${ }^{31}$ Healthcare rationing is common in all parts of healthcare and in all resource levels, however the rationing required for ICU care in a low-resource setting is an extreme form, as demand is so much greater than current supply, and the consequences for the individual are so life-threatening. The provision of some, but not sufficient, ICU care can lead to rationing decisions that are ethically, practically and for the responsible healthcare provider, emotionally challenging. Providing ethical guidance for rationing decisions in Malawian critical care is not easy. In general terms, the patients who would benefit most from critical care are the ones who should receive it. ${ }^{32}$ This involves clinical decisions that excludes patients who are "too well" and can be managed without critical care, and those who are "too sick" and require palliative care. In practice, making this judgement is difficult, and the ethically inferior "first come, first served" principle is often resorted to. ${ }^{33}$ Clear, setting-specific triage guidelines may help health workers make rationing decisions, such as those included in the ICU Handbook in Queen Elizabeth Central Hospital. ${ }^{34}$

\section{ICU provision and other health spending}

The notion of rationing is not only limited to ethically weighing how many patients will benefit from ICU care when there is clear scarcity, but what other health care goods and services compete for the resources required to run and maintain an ICU. As Scheunemann and White write, "Rationing can occur at multiple levels. Macro-allocation occurs at a societal level and includes decisions about how to allocate funds across a range of public goods, for example, education, infrastructure, defence or public health". ${ }^{29}$

In Malawi, decisions about how to allocate funds across a range social goods are challenging given that $40 \%$ of the overall national budget is funded by internationals donors like the World Bank, the International Monetary Fund, the African Development Bank, Britain, German, Norway and the USA. Currently, government funding is the main source of health financing in Malawi. Additionally, the Government of Malawi is a signatory to the Abuja Declaration, which asks member states to commit to spending at least $15 \%$ of the national budget on health. ${ }^{34}$ While Malawi did reach its Abuja goal in the 2008/2009 fiscal year, devoting 15.9\% of the budget to health, the proportion of the budget dedicated to health has fallen steadily since then. The steepest drop came in the 2014/2015 budget, when the health budget fell to $8.8 \%$ of the total share of the government's budget on health expenditures, down from $11.9 \%$ in the previous year. ${ }^{36}$ This was because donors were reluctant to support the national budget in the aftermath of the national corruption scandal in 2013 known as "cashgate".

Resources for health are limited in Malawi - on average US $\$ 30$ per year is spent on health for each Malawian.? Moreover, Malawi faces significant health challenges in the areas of HIV \& AIDS, Malaria, TB, pneumonia, diarrheal diseases and the rise of non-communicable diseases. The lack of financial resources for health and the huge demands of a sick population provide the underlying context for decisions concerning the role of ICUs. ${ }^{37}$ The primary principle and reason for the establishment of ICUs in Malawi is beneficence: acting to benefit patients by sustaining life, treating illness, and relieving pain: a laudable goal. However, this goal has to be balanced with the principle of justice in the appropriate allocation of limited resources in Malawi where resources are limited and the budgetary allocation of funds is made according to population size and not the availability or resource-level of health facilities.

Improving population health outcomes should be the primary goal of the health system. Employing a utilitarian argument involves weighing up the cost-effectiveness of each healthcare intervention - how many lives are saved and at what cost? This may lead to a conclusion that basic critical care would be highly cost-effective - the simple actions constituting basic critical care as described above - could save lives with minimal costs. Widespread, basic critical care would also be consistent with population justice. Advanced ICU care may be harder to justify, because of the cost of intensive care for each individual patient and its limited availability. There are, however, counter-arguments to this somewhat simplistic view. Well directed intensive care may indeed be cost-effective, for example, when used for a limited time for patients who are unstable in the immediate post-operative period. ICU care using simple treatment protocols that are not resource intensive can save lives. ${ }^{38}$ Furthermore, intensive care may improve hospital morale - "we are able to provide good care to our sickest patients" - and an ICU may be seen as a "centre of excellence" where teaching, supervision and good quality care can diffuse out from the ICU to the rest of the hospital and to the rest of the health system. While these effects are hard to observe, interventions originating in ICUs such as outreach and Rapid Response Teams have had hospital-wide positive impacts. ${ }^{39,40}$ Furthermore, ICUs can enable complex surgery and other advanced therapies to be carried out which in turn may be cost-effective. Weighing up the pros and cons is of vital importance but is challenging and unfortunately there is little research evidence to provide guidance. 


\section{The solution?}

We would like to suggest that the priorities for health spending ought to focus on distributive justice. That is, making decisions so as to produce the most good given the amount of the national budget that is being allocated to health. ${ }^{29}$ The solution may lie in an expansion of critical care services using a model that offers a cost-efficient approach to health care expenditure, yet still provides a form of care that is beneficial for a large pool of patients. HDUs that provide critical care or ICUs that focus on excellent basic critical care could be the middle ground that this ethical dilemma is searching for. Critical care for many patients including the basics of life support, resuscitation and supportive care may offer an effective and cost-effective option in low-resource settings like Malawi..$^{41,42}$ Building the capacity of HDUs, and ensuring that the principles of good basic critical care are carried out wherever ICUs are found would allow for the provision of services anchored on utilitarian grounds, one that focuses on achieving the greatest good for the greatest number of people also known as "The Greatest Happiness Principle". ${ }^{43}$

\section{Conclusions}

Health care balances the ethical principles of beneficence and justice. The best possible care for individual patients must be balanced with providing fair care for the whole population by ensuring limited resources are used in the most effective way. Basic critical care providing the first-level lifesaving interventions required by critically ill patients may be the ideal form of critical care. Intensive Care Units may also have a role for selected patients and as centres of excellence that raise quality for all services. It is crucial that policy makers and clinicians are aware of the huge need for good quality critical care and also the potential conflict between beneficence and justice and advocate for optimal solutions. Further debate is certainly warranted, as is research into the impact, costs and ethical implications of ICUs and HDUs in low-resource settings such as Malawi.

\section{Competing interests}

LMT is the editor-in-chief of the Malawi Medical Journal but was not involved in the processing or peer review of this article, and she did not have any influence on the decision to accept this article for publication. Both other authors declare that they have no competing interests related to this work.

\section{References}

1. Adhikari NK, Fowler RA, Bhagwanjee S, Rubenfeld GD. Critical care and the global burden of critical illness in adults. Lancet. 2010;376(9749):1339-46.

2. Vincent JL. Critical care--where have we been and where are we going? Critical care (London, England). 2013;17 Suppl 1:S2.

3. Mock C, Kobusingye O, Joshipura M, Nguyen S, Arreola-Risa C. Strengthening trauma and critical care globally. Current opinion in critical care. 2005;11(6):568-75.

4. Requejo JH, Merialdi M, Bustreo F. Improving global maternal health: progress, challenges, and promise. Current opinion in obstetrics \& gynecology. 2011;23(6):465-70.

5. Cheng AC, West TE, Limmathurotsakul D, Peacock SJ. Strategies to reduce mortality from bacterial sepsis in adults in developing countries. PLoS medicine. 2008;5(8):e175.

6. Chokotho L, Mulwafu W, Jacobsen KH, Pandit H, Lavy C. The burden of trauma in four rural district hospitals in Malawi: A retrospective review of medical records. Injury. 2014;45(12):2065-70.
7. WHO. World Health Statistics. Geneva; 2015.

8. Mgawadere F, Unkels R, Kazembe A, van den Broek N. Factors associated with maternal mortality in Malawi: application of the three delays model. BMC pregnancy and childbirth. 2017;17(1):219.

9. Tan SS, Bakker J, Hoogendoorn ME, Kapila A, Martin J, Pezzi A, et al. Direct cost analysis of intensive care unit stay in four European countries: applying a standardized costing methodology. Value in health : the journal of the International Society for Pharmacoeconomics and Outcomes Research. 2012;15(1):81-6.

10. Parikh CR, Karnad DR. Quality, cost, and outcome of intensive care in a public hospital in Bombay, India. Critical care medicine. 1999;27(9):1754-9.

11. Meiring Pde V, Lumsden JD, Morrison AG, Furnham LA. An intensive care unit in a provincial general hospital. South African medical journal $=$ Suid-Afrikaanse tydskrif vir geneeskunde. 1969;43(26):806-10.

12. Baker T. Critical care in low-income countries. Trop Med Int Health. 2009; 14(2):143-8.

13. Dunser MW, Baelani I, Ganbold L. A review and analysis of intensive care medicine in the least developed countries. Critical care medicine. 2006;34(4):1234-42.

14. Baker T. Pediatric emergency and critical care in low-income countries. Paediatr Anaesth. 2009;19(1):23-7.

15. Okech U, Chokwe T, Mungayi V. The Operational setup of Intensive Care Units in a Low Income Country in East Africa. East African Medical Journal. 2015;92(2):72-80.

16. Baelani I, Jochberger S, Laimer T, Otieno D, Kabutu J, Wilson I, et al. Availability of critical care resources to treat patients with severe sepsis or septic shock in Africa: a self-reported, continent-wide survey of anaesthesia providers. Critical care (London, England). 2011;15(1):R10.

17. Dellinger RP, Levy MM, Rhodes A, Annane D, Gerlach H, Opal SM, et al. Surviving Sepsis Campaign: international guidelines for management of severe sepsis and septic shock, 2012. Intensive care medicine. 2013;39(2):165-228.

18. Jacob ST, Moore CC, Banura P, Pinkerton R, Meya D, Opendi P, et al. Severe sepsis in two Ugandan hospitals: a prospective observational study of management and outcomes in a predominantly HIV-1 infected population. PloS one. 2009;4(11):e7782.

19. Ilori IU, Kalu QN. Intensive care admissions and outcome at the University of Calabar Teaching Hospital, Nigeria. Journal of critical care. 2012;27(1):105 e1-4.

20. Towey RM, Ojara S. Practice of intensive care in rural Africa: an assessment of data from Northern Uganda. African health sciences. 2008;8(1):61-4.

21. Gombar S, Ahuja V, Jafra A. A retrospective analysis of obstetric patient's outcome in intensive care unit of a tertiary care center. Journal of anaesthesiology, clinical pharmacology. 2014;30(4):502-7.

22. Frikha N, Mebazaa M, Mnif L, El Euch N, Abassi M, Ben Ammar MS. [Septic shock in a Tunisian intensive care unit: mortality and predictive factors. 100 cases]. La Tunisie medicale. 2005;83(6):320-5.

23. Baker T, Blixt J, Lugazia E, Schell CO, Mulungu M, Milton A, et al. Single Deranged Physiologic Parameters Are Associated With Mortality in a Low-Income Country. Critical care medicine. 2015;43(10):2171-9.

24. Gundo R, Lengu ES, Maluwa A, Mtalimanja O, Chipeta D, Kadyaudzu C. An Audit of Admissions to Intensive Care Unit at Kamuzu Central Hospital in Malawi. Open Journal of Nursing. 2014;4:583-9.

25. Gondwe WTM, Bhengu BR, Bultemeier K. Challenges encountered by intensive care nurses in meeting patient's families needs in Malawi. African Journal of Nursing and Midwifery. 2011;13(2):92-102.

26. Prin M, Itaye T, Clark S, Fernando RJ, Namboya F, Pollach G, et al. 
Critical Care in a Tertiary Hospital in Malawi. World journal of surgery. 2016;40(11):2635-42.

27. Campbell A. Bioethics the basics. New York: Routledge; 2013.

28. Kilner JF. Health care in resource allocation: Microallocation and microallocation. The Encyclopedia of Bioethics, 3rd ed. New York: Macmillan; 2004.

29. Scheunemann LP, White DB. The ethics and reality of rationing in medicine. Chest. 2011;140(6):1625-32.

30. Cook D, Giacomini M. The sound of silence: rationing resources for critically ill patients. Critical care (London, England). 1999;3(1):R1R3.

31. Lanken P. Fair allocation of intensive care unit resources. American Thoracic Society. American journal of respiratory and critical care medicine. 1997;156(4 Pt 1):1282-301.

32. Bayer R, Gaare Bernheim R, Crawley L-V M, Daniels N, Goodman K, Kass N, Low B, Rosenbaum S, Ruger JP, Sankar P, Wheeler MC, Wolf $\mathrm{L}$. Ethical considerations for decision-making regarding allocation of mechanical ventilators during a severe influenza pandemic and other public health emergency. In: http://www.cdc.gov/about/pdf/advisory/ ventdocument release.pdf Accessed 14 August 2017

33. Aacharya RP, Gastmans C, Denier Y. Emergency department triage: an ethical analysis. BMC Emerg Med. 2011;11:16.

34. QECH ICU. ICU Handbook. Blantyre, Malawi2017.

35. WHO. The Abuja Declaration: Ten Years On. Geneva: World Health
Organization; 2011.

36. Mbuya-Brown R. Health Budget Advocacy: A Guide for Civil Society in Malawi. Washington, DC: Futures Group, Health Policy Project; 2015.

37. Basnet S, Adhikari N, Koirala J. Challenges in setting up pediatric and neonatal intensive care units in a resource-limited country. Pediatrics. 2011;128(4):e986-92.

38. Baker T, Schell CO, Lugazia E, Blixt J, Mulungu M, Castegren M, et al. Vital Signs Directed Therapy: Improving Care in an Intensive Care Unit in a Low-Income Country. PloS one. 2015;10(12):e0144801.

39. Endacott R, Eliott S, Chaboyer W. An integrative review and metasynthesis of the scope and impact of intensive care liaison and outreach services. Journal of clinical nursing. 2009;18(23):3225-36.

40. Maharaj R, Raffaele I, Wendon J. Rapid response systems: a systematic review and meta-analysis. Critical care (London, England). 2015;19(1):254.

41. Gosselin RA, Thind A, Bellardinelli A. Cost/DALY averted in a small hospital in Sierra Leone: what is the relative contribution of different services? World journal of surgery. 2006;30(4):505-11.

42. Riviello ED, Letchford S, Achieng L, Newton LW. Critical care in resource-poor settings: lessons learned and future directions. 2011;39(4):860-7.

43. Cave P. Ethics: A Beginner's Guide. London, England: Oneworld Publications; 2015. 